\title{
Violations of Grice`s Maxims in The Prince and the Pauper Movie
}

\author{
Antonius Waget \\ English Language Education Study Program \\ Sanata Dharma University
}

\begin{abstract}
Proper responses must be provided interlocutors to make conversation productive and meaningful. However, interlocutors do not always provide proper responses because they do not even know conversation rules. Grice coins 4 maxims as general rules to govern daily conversation. The maxims are Quantity, Quality, Relevance, and Manner. Conversation occurs in the real daily interaction also in arts including movies. The Prince and the Pauper movie is one of the media for human daily conversation. Some parts of the movie contains violations of Grice 's maxims by the characters. Based on this background, the writer intends to explore violations of Grice's maxims in the movie and analyze the purposes of the violations. To achieve these objectives, the writer formulates two research problems: (1) Which of Grice's maxims are violated by the addressees in The Prince and the Pauper movie? (2) For what purposes do the addressees violate the maxims? The base of this research is a movie script as document. Thus, the writer uses document analysis as the method of this research. Grounded on the analysis, the writer finds that the characters, especially Prince, Tom Canty, King, and the Earl of Hertford in the movie dialogues violate the four of Grice's maxims. When failing to provide sufficient information, telling lie to their addressers, providing irrelevant glosses, and failing to be true, brief, univocal, and orderly, they respectively violate maxims of Quantity, Quality, Relevance, and Manner. Moreover, the writer finds that the characters violate the maxims in order to mislead the counterparts, be polite, save face, avoid discussion, and communicate self-interest.
\end{abstract}

Keywords: Grice`s maxims, maxim violations, The Prince and the Pauper movie.

\section{A. INTRODUCTION}

In a conversation, an addressee is expected not only to understand the content and intention of the utterance, but is also expected to provide a particular response to addresser`s speech act. The response should be mutually dovetailed with the addresser's utterance. In other words, the addressee`s utterance must have the same content and intention with the addresser's (Skinner, 1948, p. 33). By so doing, both addressee and addresser make the conversation productive and meaningful. In order to have a productive and meaningful conversation, the speakers need certain rule helping them provide their responses accordingly. H. Paul Grice comes up with his four maxims to govern the speakers to provide their speeches productive and meaningful.

This study basically employs pragmatics as the main trajectory of linguistics area to cover the analysis on maxim violations in speeches made by characters in The Prince and the Pauper movie. Leech (1992, p. 19) says that pragmatics deals with "how the utterances have meanings in situations." In favor of the statement above, Yule (1996, p. 3)claims "Pragmatics is the 
study of contextual meaning." Consenting these ideas, Sandra, Ostman, and Verschueren (2009, p. 67) say "Pragmatics provides the specific meaning, given a reference in time, place, and other contexts." The above claims emphasize how speakers organize their utterances in accordance with who they are talking to, where, when, and under what circumstances.In this sense, the language meaning is determined within situation or context of the conversational speech.

\section{B. REVIEW OF RELATED LITERATURE}

In order to support this paper, the writer would like to review four related literatures that consists of four points. They are Cooperative Principle, Politeness Principle, and Face Principle. Each of the four theories is explained as follows.

\section{Cooperative Principle}

In order to guide interlocutors in conversation, Grice (2004) posits a general rule called Cooperative Principle. The principle says "Make your conversational contribution such as is required, at the stage at which it occurs, by the accepted purpose or direction of the talk exchange in which you are engaged" (Grice, 2004, p. 45). Commenting on this paradigm, Saeed (2003, p. 204) calls Cooperative Principle as "a kind of tacit agreement by speakers and listeners to cooperate in communication." The principle contains four maxims, which are also called Grice's maxims.The Maxims are Quality, Quantity, Relevance and Manner(Grice, 2004, p. 48).

Maxim of Quantity is concerned with the amount of information to be provided in a conversation (Dornerus, 2005, p. 5). This means that when providing ideas, speakers should provide their sufficient and specific supporting details. Grice (2004) coins two sub-maxims falling under the category of quantity: "Make your contribution as informative as required (for the current purposes of the exchange)" and "Do not make your contribution more informative than required" (p. 45). In this sense, speakers should provide information that is as much helpful to them as it is for their addressees. Thus, the information should be neither too little nor too much.

The Maxim of Quality deals with the matter of giving the right information (Dornerus, 2005, p. 5). This maxim requires speakers to genuinely and sincerely provide information. The information should be as truthful and as convincing as required. Grice (2004) postulates two sub-maxims falling under the category of quality: "Do not say what you believe to be false," and "Do not say that for which you lack adequate evidence" (p. 47). This means that when giving information, the speaker should be honest. By the same token, the speaker should provide enough proof supporting his/her information or argumentation.

Maxim of Relevance is concerned with the relevance of information provided by speakers. In a conversation, addressers and addressees should make their exchanges dovetailed mutually. In this category, Grice (2004) only places a single sub-maxim, namely "be relevant" (p. 46).

Dornerus (2005, p. 5) underlines that Maxim of Manner deals with "matter of being clear and orderly when conversing. "This maxim comprises four sub-maxims, namely "Avoid obscurity of expression," "Avoid ambiguity," "Be brief," and "Be orderly" (p. 46). This paradigm clearly discloses that speakers are supposed to provide information that is clear, concise, univocal, and orderly. In other words, speakers should not make wordy utterances with multiple ways of interpretation.

\section{Politeness Principle}

Leech (1992) is the first sociolinguist who criticizes Grice's Cooperative Principle. In connection with speech content, he takes Grice's Cooperative Principle for granted that 
it enables one participant in a conversation to communicate on the assumption that the other participant is being cooperative," (p. 82). In this respect, the Cooperative Principle regulates interlocutors in providing their contributions. On the other hand, in connection with social and psychological orientation, Leech rejects the Cooperative Principle because "it cannot explain why people are often so indirect in conveying what they mean" (1992, p. 80).

Grounded on his criticism aforementioned, Leech (1992, pp. 131-133) postulates a Politeness Principle that is to coexist with Grice's Cooperative Principle to solve the problem. He claims that Grice's maxims are violated in conversations because the speakers tend touphold politeness. There are six sub-maxims embodied in his Politeness Principle.

(1) Tact Maxim (in impositives and commissives)

(a) Minimize cost to others

[(b) Maximize benefit to others]

$=$ Imply less cost to others and imply benefit to others

(2) Generosity Maxim (in impositives and commissives)

(a) Minimize benefit to self

[(b) Maximize cost to self]

$=$ Imply less benefit to self and imply cost to self

(3) Approbation Maxim (in expressives and assertives)

(a) Minimize dispraise of others [(b)

Maximize praise of others]

$=$ Avoid saying unpleasant things about others

(4) Modesty Maxim (in expressives and assertives)

(a) Minimize praise of self [(b) Maximize dispraise of self]

$=$ Avoid saying pleasant things about self
(5) Agreement Maxim (in assertives)

(a) Minimize disagreement between self and others

[(b) Maximize agreement between self and others]

(6) Sympathy Maxim (in assertives)

(a) Minimize antipathy between self and others

[(b) Maximize sympathy between self and others].

\section{Face Saving}

In a face-to face talk, speakers tend to say things in a wordy way, dishonestly, and ambiguously. Goffman (2008) pointedly states that in order to save face, speakers tend to "employ exaggeration, circumlocutions, deceptions, and irrelevance glosses so that the others' facesare preserved" (p. 17). He defines face as an individual's "image of self delineated in terms of social attributes - albeit an image that others may share as when a person makes a good showing for his profession or religion by making a good showing for himself" (Goffman, 2008, p. 5). In this sense, face refers to a speaker's self esteem depicted in daily interaction. Referring to this, Brown and Levinson (1987, p. 61) define face as "something that emotionally invested, and that can be lost, maintained, or enhanced, and must be constantly attended to in interaction."

\section{RESULTS AND DISCUSSION}

As mentioned earlier, the writer analyses The Prince and the Pauper movie to observe what Grice`s Maxims are violated and to examine the purposes the addressees violate the maxims. The aim is to answer two research problems, namely what Grice`s maxims are violated and what purposes of the violations found in the movie by looking at the conversations between the characters.

The movie contains a lot of dialogues with violations of Grice`s maxims, which 
will become a rich sample for the analysis. The setting creates the possibility of maxims violation on the addressees' utterances. The violation occurs within the circumstances of the royal family and in those of the peasant's life.

\section{Violations of Grice's Maxims in The} Prince and the Pauper movie

The writer uses Grice's theory of Cooperative Principle to answer the first research question, namely which Grice`s maxims are violated in The Prince and the Pauper movie. Four characters: Prince, Tom Canty, King, and the Earl of Hertfordare employed because they are the characters violating the maxims the most. They violate all of the maxims. What makes difference is, as seen in the table, the frequency of the occurrences of the violation and who employs the violation in the 24 dialogues.

When failing to provide sufficient and supporting information and contribute information more than is required,the speakers violate the Maxim of Quantity. When providing information, the speakers may tell a lie or fail to back up their statements with enough evidence, they violate the Maxim of Quality. When deliberately making their information irrelevant to the purpose of the exchange, the speakers violate the Maxim of Relevance. When providing wordy utterances with multiple ways of interpretation, the speakers violate the Maxim of Manner.

Table 4.1: Maxim Violation by the Characters in The Prince and Pauper Movie

\begin{tabular}{|l|l|c|}
\hline \multicolumn{1}{|c|}{ Maxim } & \multicolumn{1}{|c|}{ Character } & \multicolumn{1}{|c|}{ Number } \\
\hline Quantity & $\begin{array}{l}\text { Prince (1), Tom Canty (5), King (-),and the Earl of } \\
\text { Hertford (2) }\end{array}$ & 8 dialogues \\
\hline Quality & $\begin{array}{l}\text { Prince (-), Tom Canty (2), King (-),and the Earl of } \\
\text { Hertford (-) }\end{array}$ & 2 dialogues \\
\hline Relevance & $\begin{array}{l}\text { Prince (1), Tom Canty (2), King (2), and the Earl of } \\
\text { Hertford (5) } \\
\text { Manner }\end{array}$ & $\begin{array}{l}\text { Prince (2), Tom Canty (1), King (1), and the Earl of } \\
\text { Hertford (-) }\end{array}$ \\
\hline \multicolumn{1}{|c}{ TOTAL } & 24 \\
\hline
\end{tabular}

The table shows that the maxims (Quantity, Quality, Relevance, and Manner) are respectively violated $8,2,10$, and 4 times. The characters involved in the dialogues are the Prince, Tom Canty, the King, the Earl of Hertford, Doctor 1, and Fr. Andrew. The characters that violate the maxims are Prince, Tom Canty, King, and the Earl of Hertford when taking roles as addressees.

The Prince violates Maxims of Quantity (1), Relevance (1), and Manner (2). Tom Canty violates the Maxims of Quantity (5), Quality (2), Relevance (2), and Manner (1). The King violates the Maxims of Relevance (2) and Manner (1). the Earl of Hertford violates the Maxims of Quantity (2) and Relevance (5).

a. Violations of Maxim of Quantity in The Prince and the Pauper movie

This maxim deals with the amount of information in a conversation. It requires speakers to contribute sufficient information as is required (Grice, 2004, p. 45). However, in point of fact, speakers cannot always fulfill the maxim. It is clearly seen in Dialogues 1 .

\section{Dialogue 1}

Context: Dialogue 1 takes place at Cathedral, the coronation place. After all of the 
coronation attendances leave the Cathedral; it is only the Prince and Tom Canty. Realizing that Tom Canty has done a great job of being a prince, Edward Tudor,the real prince, calls Tom Canty to sit down next to him. However, Tom Canty wonders if he as a proletariat deserves sitting next to him. The Prince assures Tom Canty that it does not matter.
[1] Prince : Tom
[2] Tom Canty : Yes, sire, your higheness
[3] Prince : Come here
[4] Tom Canty : Yes Sir, they are gone?
[5] Prince : : Sit down.
[6] Tom Canty : Are you sure it`s all right?
[7] Prince : You sat down all the time when your were King, so I suppose it won't matter now.

The response [7] in Dialogue 1 apparently violates the Maxim of Quantity. The reason is the Prince fails to make his contribution as informative as is required and fails to make his contribution more informative than the situation requires (Grice, 2004, p. 45). Tom Canty's question [6] mostly demands the Prince for a short response as stated in his last sentence [7], namely I suppose it won't matter now. However, what Tom Canty receives from the Prince is a too wordy answer as said in the beginning containing the urchin's action of replacing him as a king while he was out of the palace. Tom Canty actually does not need such unnecessary answer. Grice considers such an answer as wasting time (Grice, 2004, p. 46).

The Prince's wordy description gives rise to implicature that he very well understands Tom Canty's situation and psychological strains while he was out of the palace. Now, the Prince wants to minimize Tom Canty`s inferiority and maximize praise of him (Leech, 1992, p. 123). Besides that, the Prince wants Tom Cantyto feel untroubled by fear. In this sense, the Prince deliberately violates the Maxim of Quantity in order to express his politeness and save Tom Canty`s face.

\section{b. ViolationofMaxim of Quality in The Prince and the Pauper Movie}

Maxim of Quality enjoins speakers to provide true information (Grice, 2004, p. 46). Thus, the speakers must be honest with their utterances when providing information. In addition, speakers have to back up their contributions with clear evidence or they would be stamped liars. Dialogue 2 shows evidence of the violations by telling white lies.

\section{Dialogue 2}

Context: Dialogue 2 takes place at Fr. Andrew's office. Instead of begging farthings for his father, Tom Canty decides to play royal installment with his friends on a playground. Seeing that, the cruel father gets very angry, beats and flings him onto the pond of mud then ruthlessly leaves him there. Soon after that, Tom Canty comes over to Fr. Andrew's house. He still looks gloomy with some traces of tears running down his cheeks, blisters on his arms, and mud on all over his body and shabby clothes. Seeing such a weird appearance, Fr. Andrew asks him.

[1] Fr. Andrew: Thomas, have you been crying?

[2] Tom Canty: No, sir. It's sweat. You see, I've been running.

The response [2] in Dialogue 2 illustrates that Tom Canty fails to fulfill the Maxim of Quality, which demands him to be honest and true when providing his contributions. Tom Canty's response contradicts the experience he has just faced. As a matter of fact, based on Tom Canty's own real experience, the traces of tears still running down his cheeks is evidence that he has been crying. 
The implicature could be drawn here that by providing utterance [2], Tom Canty wants to say Yes, Sir, I have, or Yes, Sir, I have been crying. However, he does not dare to say so. Conversely, he denies it by obviously telling a white lie, No, sir. It's sweat. Even, Tom Canty prolongs his white lies by saying You see, I've been running. Nevertheless, Tom Canty cannot prove this last utterance because he really only comes straight from the playground where he is beaten and flung by his cruel father. Based on these facts, by saying You see, I've been running, Tom Canty wants to say, as the implicature, You see, it is true, I have been crying.

Tom Canty's answer [2] in this respect also gives rise to implicature that, in front of Fr. Andrew, he wants to appear as someone who is worthy of being loved by his father. By employing white lies, he tries to save face. Moreover, by deliberately saying white lies, Tom Canty wants tomake himself look good and loveable by his father. In so doing, Fr. Andrew gets misled into thinking that nothing wrong has happened to him and takes it for granted that he has been running and the traces on his cheeks are sweat (Grice, 2004, p. 49).

\section{c. Violation of Maxim of Relevance in The Prince and the Pauper Movie}

Grice (2004) posits one maxim called "be relevant" (p. 46). This maxim governs speakers to produce a mutually dovetailed conversation. However, it is not every time speakers abide by the maxim as seen in Dialogues 3.

\section{Dialogue 3}

Context: Dialogue 3 takes place in the Prince`s bedroom. Soon after the King dies, the Earl of Hertford comes over to Tom Canty in the Prince's bedroom. Thinking that Tom Cantyis the real Prince, the Earl of Hertford urgently has Tom Canty designate him as the Lord High Protector in a short and simple ceremony. Whereas, Tom Canty wants to immediately go home in Offal Court since feeling more and more uncomfortable with the Royal life.

[1] Tom Canty: Can I go home now, please?

[2] Earl of Hertford: Permit me, Your Majesty. Repeat after me, and when you have finished strike my shoulder with your sword.

This extract conversation illustrates a violation of Maxim of Relevance. The Earl of Hertford's whole answer [2] does not match Tom Canty`s request [1]. The type of Tom Canty`s question [1] is open requiring an alternative answer Yes or No.Thus, the relevant answer supposed to be provided by the Earl of Hertford isYes, you can go home now, or No, you can't go home now, or No, you can't go home until you have finished strike my shoulder with your sword.

The Earl of Hertfort's gloss Permit me, Your Majesty implies that he still believes that Tom Canty is the real Prince of Wales. Being a Prince, his home is the palace; there is no other place for him. Thus, he does not allow Tom Canty to go anywhere. The gloss Repeat after me implies that the Earl of Hertford very well memorizes the rite formulation of designation and it is assumed that Tom Canty does not know the formulation. Striking the shoulder of the installed person with a sword closes the official ceremony. That is the reason why the Earl of Hertford says to Tom Canty, When you have finished, strike my shoulder with your sword.

Dornerus (2005) says that one of the purposes of violating Maxim of Relevance is to communicate the speakers' interests (15). It is clear that from the discourse, the Earl of Hertford violates the Relevance Maxim in order to communicate his own interest by ignoring Tom Canty`s inquiry 
and protracting the proper answer. The Earl Hertford`s interest is an installment of being a Lord High Protector.

\section{d. Violation of Maxim of Manner in The Prince and the Pauper Movie}

In his book entitled Logic and Conversation, Grice (2004) underlines that speakers in their conversations "have to avoid obscurity of expression, avoid ambiguity, avoid unnecessary prolixity (be brief), and be orderly" (p. 46). Thus, Maxim of Manner deals with perspicuousness of disclosures provided by speakers. When giving information, speakers must avoid unnecessary redundancy, obscurity, and ambiguousness. However, as a matter of fact, speakers cannot always carry out the requirements. It is clearly seen in Dialogue4.

\section{Dialogue 4}

Context: Dialogue 4 takes place at the King's bedroom. While talking with the Prince, the King snatches a piece of biscuit from the Prince's hand and eats it. Soon after that two of his doctors come over. To them, the biscuits could deteriorate the King's health. Seeing the King in an unsound state eating biscuit, one of them interrogates him. Hearing the unexpected doctor 1's interrogation, the King feels offended and furious. In this situation, the King disorderly and obscurely answers the doctors.

[1] Doctor 1: Your Majesty, can that be a biscuit?

[2] King : (Looking at the doctors with angry eye and loudly shouting at them) What do you think it is, the Archbishop's head? Arrr....

The King's response [2] in the form of question to doctor 1's rhetorical question [1] depicts a violation of Maxim of Manner because he utters an obscure and disorderly response. Doctor 1 only wants to know if it is a biscuit eaten by the King. Thus, the King is supposed to answer only Yes, it is or Yes, it is a biscuit or No, it is not or No, it is not a biscuit. Since the King knows what he is eating is a biscuit, he should say Yes, it is or Yes, it is a biscuit as a proper answer. Nevertheless, the King hurls doctor 1 a question, What do you think it is, the Archbishop's head? The King, in this respect, evokes his answer obscure.

When saying Arrr...., the King makes his gloss disorderly and more obscure. The gloss, Arrr...., does not make sense but perplexes the doctors. Since the King fails to avoid obscurity and uphold the response orderly, he violates the Maxim of Manner. The King deliberately contributes such an obscure and disorderly utterance in order to avoid getting into an argument. If the King had said that what he eats was biscuit, he then should provide the argument, for example the reason he eats the biscuit, the benefits of eating the biscuit, et cetera.

Since the King fails to avoid obscurity and uphold the response orderly, he violates the Maxim of Manner. After all, the King deliberately contributes such an obscure and disorderly utterance in order to save face(Goffman, 2008, p 17). If the King has said that what he eatsis biscuit, he then gets himself into a debate that is losing his face amongst the society. If the doctors knew that it is biscuit, the doctors would impose on him a stricter rule, for example No food containing wheat at all or No food in the bed. The stricter rule would lose his face as a King for the whole English empire. Thus, in order to save face, the King deliberately does not say the word biscuit.

\section{Purposes for the Maxim Violations}

The core aim of this part is to address the second research problem, namely for what purposes do the characters violate the maxims. In order to solve this problem, the writer elaborates three theories, namely Cooperative Principle coined by Grice (2004), 
Politeness Principle coined by Leech (1992), and Face Principle coined by Goffman (2008). Each theory provides the reasons speakers violate Grice's maxims. Besides that, the writer employs Dornerus' viewpoint of the purposes for violating the maxims.

\section{a. Misleading Counterparts}

Tom Canty, in Dialogue 2, is inclined to produce statement, which misleads Fr. Andrew as his counterpart in conversations. Realizing that Fr. Andrew would ask him for more information leading to the truth if he only said No, sir. This thought triggers him to mislead Fr. Andrew by immediately adding false and unnecessary glosses, namely It's sweat. You see, I've been running. Grice(2004, p. 49) underlines that misleading counterparts is one of the purposes of the maxims violations in daily exchanges. Misleading in this sense means that the speaker gives wrong information to counterpart and makes the counterpart believe it or take it for granted.

Grounded on the state of believing each other, Fr. Andrew believes Tom Canty and takes his convincing gloss for granted. In so doing he believes that no accident has happened to Tom Canty or nothing has happened between Tom Canty and his father and he does not need to see Tom Canty's father. Tom Canty's false information impresses Fr. Andrew to think and believe that he has a good and loving father.

\section{b. Being Polite}

Leech (1992, pp. 81-82) claims that in a particular situation, speakers may violate Grice's maxims by changing unpleasant topic of conversation or adding additional unnecessary glosses or even tell white lies in order to be polite. In Dialogue 1, the Prince deliberately provides additional information, You sat down all the time when your were King, in his proper answer, I suppose it won't matter now. By minimizing Tom Canty's feeling of inferiority and maximizing Tom
Canty`s praise of him, the Prince wants to show his politeness towards Tom Canty.

\section{c. Saving Face}

Saving face is one of the aims the speakers want to reach when violating Grice's maxims. Goffman, (2008, p. 17) claims that by employing exaggeration (quantity) or deceptions (quality) or circumlocutions (manner) irrelevance (relevance) in a face-to face talk, speakers violate Grice's maxims in order to preserve their self-esteem or dignity. The characters, the Prince, TomCanty, and king in The Prince and the Pauper movie violate Grice's maxims of Quantity, Quality, and Manner in order to save their own faces and others' (Brown \& Levinson, 1987, p. 61). When providing the long gloss in Dialogue 1, You sat down all the time when your were King, so I suppose it won't matter now, the Prince tries to bluntly and honestly say to Tom Canty his appreciation for replacing him as the prince while he was out of the palace. It is the time for the Prince to give Tom Canty security and maintain his self-esteem as a real ordinary person. Thus, by providing the wordy utterance, the Prince wants to save Tom Canty`s face.

Tom Canty, in Dialogue 2, violates Maxim of Quality in order to save his own and his father's self-esteem as a good child and father (Brown \& Levinson, 1987, p. 61). Tom Canty does not want to disgrace his father in front of Fr. Andrew by revealing his father's evil doing towards him. Tom Canty also does not want Fr. Andrew to see him as a troublesome boy. By concealing all the things that have happened to him on the playground, Tom Canty saves his father's face and his own.

Posing doctor 1 a rhetorical question in Dialogue 4, The King tries to save his face, which was threatened by the doctor's critical question, Your Majesty, can that be a biscuit? If the King had honestly answered the question Yes, it is biscuit, he would find himself in 
trouble, guilty, and lost face. Thus, the safe response is a rhetorical question. However, the question becomes obscure when the King adds another question that seems irrelevant, the Archbishop's head? The King means Archbishop Fisher who does not agree with his marriage with Katherine of Aragon in 1534 (Mayer, 1989, p. 235). The king and his followers were even excommunicated from Rome. It can be understood why the King makes such a disclosure. The King feels that the doctoris as strict and cruel as Archbishop Fisher. The King finds himself restricted in front of the rules and laws from the doctor and the Archbishop.

\section{d. Avoiding Discussion}

In truth, in a conversation, speakers may encounter an unpleasant discussion. In order to avoid getting into unpleasant situation, speakers deliberately provide disordergloss and more obscure (Goffman, 2008, p. 17). When interrogated by doctor 1, in Dialogue 4, the King finds himself in an unpleasant situation. Realizing himself eating biscuits containing wheat, the King straight away in a high tone poses the doctor a rhetorical question What do you think it is, the Archbishop's head? If he had said what he is eating was a biscuit, the doctor would ask him about the biscuit, the reason he is eating it, what he is feeling, et cetera. When posing this gloss, the King hopes that the doctor gives him an answer, which frees him from discussion.

\section{e. Communicating Self-interest}

Dornerus (2005, p. 15) says that violating maxims in order to communicate self-interest is one of the goals to be reached by speakers in their conversations. Dialogue 3 shows that the Earl of Hertford purposely violates the Maxim of Relevance to communicate his self-interest. His interest is to be designated as the Lord High Protector in England. In order to reach his goal, the Earl of Hertford deliberately ignores Tom Canty's request of leaving for his home in Offal Court.

\section{CONCLUSION}

Grounded on the research, the writer comes up with two conclusions. The first conclusion is that the four charactersinThe Prince and the Pauper movie - Prince, Tom Canty, King, and the Earl of Hertford -on purpose violate all of Grice's maxims. The maxims being violated are Quantity, Quality, Relevance, and Manner. When providing insufficient, dishonest, irrelevant, and unclear information, the characters respectively violate the Maxims of Quantity, Quality, Relevance, and Manner. The character who violates the maxims most is Tom Canty. In 24 dialogues, he 10 times violates the maxims. The maxim he violatesthe most is Maxim of Quantity.

The second conclusion is that in certain situation, the four characters cannot prevent themselves from violating Grice's maxims. The characters tend to intentionally violate the maxims in order to achieve certain purposes. By intentionally violating the four maxims in order to mislead counterpart, be polite, save face, avoid getting into an argument, and communicate self-interest.

\section{REFERENCES}

Brown, P. \& Levinson, S. C. (1987).Politeness: Some universals in language usage ( $3^{\text {rd }}$ ed.). Cambridge: Cambridge University Press.

Dornerus, E. (2005). Breaking maxims in conversation a comparative study of how scriptwriters break maxims. In Desperate housewives and that 70's show. Retrieved on October $10^{\text {th }}, 2012$, fromhttp://www.kau. divaportal.orgsmash-getdiva.pdf.

Goffman, E. (2008). Interaction ritual: Essays on face-to-face behavior. Far Hill, NJ: Pantheon Books.

Grice, H. P. (2004). Logic and conversation. Berkeley: University of California. 
Leech, G. N. (1992). Principles of pragmatics. London: University of Lancaster.

Mayer, T. F. (1989).Thomas starkey and the commonwealth: Humanist politics and religion in the reign of Henry VIII. Cambridge:Cambridge University Press.

Saeed, J. I. (2003). Semantics (Second ed.). Malden, MA: Blackwell Publishing Ltd.
Sandra, D., Ostman, J.O., Verschueren, J. (Eds.) (2009). Cognition and pragmatics. Amsterdam: John Benjamins Publishing Company.

Skinner, B. F. (1948). Verbal behavior.New York: Appleton Century Crofts Inc.

Yule, G. (1996).The study of language $\left(4^{\text {th }} \mathrm{ed}\right.$.). Cambridge: Cambridge University Press. 